Please cite this article as: Idowu A, Olasinde $Y$, Aremu AO, Israel OK, Ala OA. Sociodemographic Factors Associated with Utilization of Oral Rehydration Therapy Among Under Five Children with Diarrhoea in a Rural Nigerian Community. Anatol J Family Med 2020;3(3):221-228.

Address for correspondence: Dr. Ajibola Idowu. Department of Community Medicine, Bowen University, Iwo, Nigeria Phone: +2348137974759 E-mail: idajibola@yahoo.com

Received Date: 14.03.2020 Accepted Date: 14.06.2020 Published online: 07.12.2020

(C) Copyright 2020 by Anatolian Journal of Family Medicine Available online at www.anatoljfm.org OPEN ACCESS

\section{Sociodemographic Factors Associated with Utilization of Oral Rehydration Therapy Among Under Five Children with Diarrhoea in a Rural Nigerian Community}

\author{
D Ajibola Idowu, ${ }^{1}$ (i) Yetunde Olasinde, ${ }^{2}$ (1) Ayodele Olatayo Aremu, ${ }^{1}$

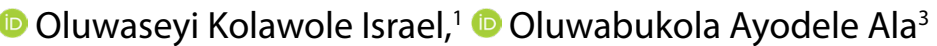 \\ 'Department of Community Medicine, Bowen University, Iwo, Nigeria \\ ${ }^{2}$ Department of Paediatrics, Bowen University, Iwo, Osun State, Nigeria \\ ${ }^{3}$ Department of Medicine, Bowen University, Iwo, Osun Sate, Nigeria
}

\section{ABSTRACT}

Objectives: This study assessed the prevalence of childhood diarrhea disease and identified associated factors of oral rehydration therapy (ORT) use in treating childhood diarrhoea in a rural Nigerian community.

Methods: A cross-sectional study design involving caregivers of under-five children with at least one episode of diarrhea in the past six months in Ejigbo, Osun-State, Nigeria was conducted using a multistage sampling method. Pretested interviewer-administered, semi-structured questionnaire was used for data collection.

Results: A total of 410 caregivers were included in the study. Two hundred and fifty-two (61.5\%) of under-five children in the study area had at least one episode of diarrhea within six months preceding the survey. Only $50(13.8 \%)$ of all the participants who were aware of ORT had good knowledge, but $312(76.1 \%)$ of them had a positive attitude to its use. ORT was utilized in treating only 145 (57.5\%) of childhood-diarrhea cases. Determinants of ORT uptake in the study population included gender ( $\mathrm{OR}=0.470,95 \% \mathrm{Cl}=1.160-3.110)$, educational status $(\mathrm{OR}=0.620,95 \% \mathrm{Cl}=2.300-4.120)$, knowledge on availability of $\mathrm{ORT}(\mathrm{OR}=3.010,95 \% \mathrm{Cl}=1.820-3.990)$ and overall ORT knowledge (OR=0.640, 95\% $\mathrm{Cl}=0.110-0.640)$.

Conclusion: The burden of childhood diarrhea disease is high in the study population. Authors advocate for improvement in the general socio-economic wellbeing of rural dwellers for this burden to be lessened. There is also an urgent need for a renewed awareness campaign on proper use of ORT in treating childhood diarrhea diseases in rural Nigeria.

Keywords: Diarrhea, prevalence, children, treatment, Nigeria

\section{INTRODUCTION}

Diarrhea has remained a leading childhood killer disease in most developing countries like Nigeria despite the availability of cost-effective treatment strategies. The World Health Organization (WHO) defines diarrhea as "the passage of three or more loose or liquid stools per day". ${ }^{[1]}$ Occurrences of this disease have been linked with poor access to potable water, poor sanitation and consumption of contaminated foods, among other factors. ${ }^{[2]}$ It has been estimated that $88 \%$ of diarrhea cases is because of unsafe drinking-water supply, inadequate sanitation and hygiene..$^{[3]}$

Diarrhea accounted for $8 \%$ of all deaths among under-five children worldwide in 2016. ${ }^{[4]}$ This shows that approximately 1300 young children die daily, and approximately 480.000 of them die annually of diarrhoea disease. ${ }^{[4]}$ The 2013 National Demographic and Health Sur- 
vey (NDHS) report for Nigeria shows that $10 \%$ of under-five children had diarrhoea episodes within two weeks preceding the survey; only $29 \%$ of the cases were taken to any health facility for care, while barely $38 \%$ of them were administered any form of oral rehydration therapy (ORT). ${ }^{[5]}$

One of the targets of the Sustainable Development Goal (SDG)-three is to reduce under-five mortality to as low as 25 per 1000 live births in every country $2030 .{ }^{[6]}$ For this target to be met, there is a need to understand the burden of some of the leading causes of childhood deaths, such as diarrhoea. Currently, there is paucity of data on the prevalence of diarrhea among under-five-children and on socio-economic factors associated with the disease and ORT utilization for its treatment among residents of Ejigbo, Osun State, Nigeria. Meanwhile, Toyobo, revealed that $47.5 \%$ of Ejigbo residents earned a monthly income of 21.000.00-30.000.00 Naira (58-82 USD); only 64 boreholes were sighted by the researcher in five electoral wards within the Ejigbo Local Government Area, and only $44 \%$ of such boreholes were fully functional. ${ }^{[7]}$ The community equally lack municipal treated water supply with no obvious coordinated sanitation policy/activities in place, which signifies that most inhabitants of the community depend on wells, rainwater and springs for drinking-water supply. ${ }^{[7]}$ Thus, the combined effects of poor socio-economic status of the people and apparent infrastructural deficits in the community necessitated this study since authors envisaged that these factors could have impacted negatively on the burden of diarrhea disease among children and diarrhoea treatment modalities in the community. ${ }^{[7]}$

ORT use remains one of the most cost-effective Public Health interventions worldwide. In the 1990s, it was estimated that more than 1 million diarrhoea-related deaths might have been averted yearly in children largely due to the use of ORT. ${ }^{[8]}$ As such, replacing lost fluids through oral rehydration salt (ORS) has been recommended by both WHO and UNICEF as the chief corner stone of diarrhoea management since 2004. ${ }^{[9]}$ However, ORT knowledge, utilization and coverage have been abysmal in most developing countries. In fact, studies have shown a disturbing decline in diarrhea management behaviour among caregivers in most countries of the world. ${ }^{[10]}$ Worst still, global coverage of ORT intervention has been observed to be extremely low in the recent past, as only $11 \%$ of deserving children are receiving it. ${ }^{[11]}$ Community-based studies, such as the current one, are thus indicated to understand factors that could be responsible for the declining ORT utilization since managing diarrhea at home is a common practice among rural mothers and other caregivers in Nigeria. ${ }^{[12,13]}$

Most previous studies have assessed the burden of diarrhoea based on the occurrence of the disease within two weeks preceding the surveys. ${ }^{[12,14]}$ Our study examined diar- rhoea in the study area over six months to have a comprehensive overview of the true burden of the disease in the rural settings. The present study aimed to assess the burden of diarrhea disease in the Ejigbo community and examine the socio-demographic variables that may be associated with ORT utilization in the treatment of the disease.

\section{METHOD}

This study was carried out over six weeks (May-June, 2019) among caregivers of under-five children in Ejigbo, Osun state, Nigeria. The community is the headquarters of Ejigbo Local Government Area with a projected population of $150.610 .{ }^{[15]}$ Yoruba constitutes the main ethnic group in the community. Most inhabitants are farmers, while Islam and Christianity are the predominant religions in the community.

Care-givers of under-five children with at least one episode of diarrhea in the past six months and who consented to participate in this study were interviewed, but caregivers who were not permanent residents of the Ejigbo community or caregivers whose children were too sick as at the time of the survey were excluded from this study.

The sample size was calculated using the Leslie-Kish formula for estimating single proportion. ${ }^{[16]}$ Based on findings from a Nigerian study conducted by Asakitikpi et al., $61 \%$ of our participants were assumed to have used ORT in treating the last episodes of diarrhoea in their children. ${ }^{[17]}$ The tolerable margin of error was set at $5 \%$, and correction for non-response was made. Thus, a minimum sample size of 408 was estimated for this study.

A multi-stage sampling technique was adopted for this research. Ejigbo ward D was firstly selected using simple random technique (balloting) out of the four electoral wards in the community. Secondly, selection by balloting of six enumeration areas within the selected ward was made. The enumeration areas selected were OkeOdo, Gaa, Oke-Moyo, Olodo, Alagba and Ajepe Areas. Lastly, the systematic sampling method was adopted in the selection of households from the selected enumeration areas. The sampling interval was estimated by dividing our sample size by the number of households in the chosen enumeration areas. Based on the number of households in an enumeration area, every $\mathrm{n}^{\text {th }}$ household was chosen but the first household was selected by a simple random method (spinning a bottle). Simple random technique (tossing a coin) was used to select participants in households with more than one eligible person.

A semi-structured interviewer-administered questionnaire was developed after reviewing similar studies and used for data collection. The questionnaire comprised 30 items and was compartmentalized into five sections. Section A and B comprised socio-demographic and housing characteristics of the participant respectively. Section C and D obtained 
information on the occurrence of acute diarrhoea disease and awareness and knowledge of ORT, respectively, while Section E collected information on the attitude of participants to ORT and diarrhoea management. The questionnaire was constructed in simple English language and was translated to the Yoruba language for participants who were more comfortable with answering in their native language. Back translation was done to the English language to preserve the original meanings of the questions. Data were collected by trained medical students undergoing rural posting in the community.

Pretesting of the instrument was carried out among 41 participants selected using the convenience sampling method in Ejigbo ward A, separate from the ward used for the main study. The pre-test exercise helped us to identify wrongly phrased items of the questionnaire and also helped to assess the internal consistency of the questions. Identified ambiguous questions were either rephrased or removed entirely.

Data were collected and edited daily before being entered into analytical software. The software used for the study analysis was Statistical Package for Social Sciences (version 21.0). The categorical variables were presented in the form of frequency, percentages, and continuous variables were presented as means, standard deviation. Chi-squared test was used to compared categorical variables at the bivariate level. Also, a stepwise binary logistic regression was carried out at the multivariate level. Variables found to be statistically significant at the bivariate level were sequentially imputed into the model. Adjusted odds ratio and confidence intervals were obtained. Results were considered statistically significant at $p<0.05$.

Ten questions were asked to assess participants' knowledge regarding causes and treatments of diarrhoea. To assess participants' causes of childhood diarrhoea, they were asked to identify which factors could be associated with childhood diarrhoea. The responses were teething problems, infections, contaminated water/foods and poor hand hygiene. Correct answers to each of the questions attracted two points. Summation was made and results converted to percentages. Participants who scored less than 50\% were categorized as having poor knowledge of ORT. Four questions were positively phrased and rated on a five-point Likert scale (Strongly agree $=5$ points and strongly disagree $=1$ point) to assess participants' attitudes towards ORT. Summation was made, and total scores converted into percentages. Participants who scored less than $50 \%$ were categorized as having poor knowledge of ORT. Participants who used either sachet ORS or prepared salt and sugar solutions at home for the treatment of last diarrhoea episodes were categorized as ORT users.

\section{RESULTS}

In this study, 430 questionnaires were administered but 410 $(95.3 \%)$ returned satisfactorily completed. The mean age of the participants was $32.2 \pm 11.4$ years and $253(61.7 \%)$ of them were Muslims. Out of the 410 households visited, 369 (90.0\%) of them had at least one toilet with water closet being the commonest type and available in 261 (63.7\%) houses. Socio-demographic characteristics of the participants are summarised in Table 1.

Table 1. Socio-demographic characteristics of the participants

\begin{tabular}{|c|c|}
\hline & Mean \pm SD \\
\hline \multirow[t]{2}{*}{ Age (years) } & $32.2 \pm 11.4$ \\
\hline & n (\%) \\
\hline \multicolumn{2}{|c|}{ Age groups of care-givers $(n=410)$} \\
\hline$\leq 20$ years & $40(9.8)$ \\
\hline$>20$ years & $370(90.2)$ \\
\hline \multicolumn{2}{|l|}{ Gender $(n=410)$} \\
\hline Male & $36(8.8)$ \\
\hline Female & $374(91.2)$ \\
\hline \multicolumn{2}{|l|}{ Religion $(n=410)$} \\
\hline Christianity & $155(37.8)$ \\
\hline Islam & $253(61.7)$ \\
\hline Traditional & $2(0.5)$ \\
\hline \multicolumn{2}{|c|}{ Educational level $(n=410)$} \\
\hline None & $71(17.3)$ \\
\hline Primary & $100(24.4)$ \\
\hline Secondary & $195(47.6)$ \\
\hline Tertiary & $44(10.7)$ \\
\hline \multicolumn{2}{|c|}{ Gender of youngest child $(n=410)$} \\
\hline Male & $197(48.0)$ \\
\hline Female & $213(52.0)$ \\
\hline \multicolumn{2}{|c|}{ Toilet present in the house $(n=410)$} \\
\hline Yes & $369(90.0)$ \\
\hline No & $41(10.0)$ \\
\hline \multicolumn{2}{|c|}{ Types of toilet in various houses $(n=369)$} \\
\hline Pit latrine & $85(23.0)$ \\
\hline VIPlatrine & $23(6.0)$ \\
\hline Water closet & $261(71.0)$ \\
\hline \multicolumn{2}{|c|}{ Sources of water $(n=410)$} \\
\hline Borehole & $151(36.8)$ \\
\hline Well & $247(60.2)$ \\
\hline Rain water & $9(2.2)$ \\
\hline River & $3(0.8)$ \\
\hline
\end{tabular}

VIPlatrine: Ventilated Improved Pit Latrine. 
The prevalence of diarrhea was estimated at 252 (61.5\%); stool was watery in 219 (86.9\%) diarrhoea episodes. Care was sought in healthcare facilities by 71 (32.9\%) of the caregivers, herbal medication was administered in 19 (8.8\%) cases, while 52 (24.0\%) of caregivers purchased other drugs (not ORS) at chemist shops for diarrhoea treatment. Treatment practices of diarrhoea in the participants are summarised in Table 2.

Three hundred sixty-two (88.9\%) of the caregivers have heard about ORT. Sachet ORT was the most popular, known by $282(78.0 \%)$ of the participants. Only $50(13.8 \%)$ of all the participants who heard of ORT possessed good knowledge of it, but $312(76.1 \%)$ of them had positive attitude to ORT use. Overall, ORT was utilized in treating only 145 (57.5\%) of diarrhea cases among under-five children in the study population. Awareness, knowledge, attitude and practice of participants on ORT are summarised in Table 3.

As shown in Table 4, ORT utilization in diarrhoea treatment was significantly associated with participants' sex, educational status and overall knowledge on diarrhoea disease. These factors remained statistically significant at the multivariate level. In Table 5, male participants had 0.470 times lesser ORT use in treating childhood diarrhoea compared with their counterparts ( $\mathrm{OR}=0.470,95 \% \mathrm{Cl}=1.160-3.110)$. Also, participants with no formal education had reduced

\begin{tabular}{|c|c|}
\hline & n (\%) \\
\hline \multirow{2}{*}{\multicolumn{2}{|c|}{$\begin{array}{l}\text { Any episode of diarrhoea in the youngest child within } \\
\text { the past six months }(n=410)\end{array}$}} \\
\hline & \\
\hline Yes & $252(61.5)$ \\
\hline No & $158(38.5)$ \\
\hline \multicolumn{2}{|l|}{ Nature of stool $(n=252)$} \\
\hline Mucus containing & $30(11.9)$ \\
\hline Blood stained & $3(1.2)$ \\
\hline Watery & $219(86.9)$ \\
\hline \multicolumn{2}{|l|}{ Any treatment given to the child $(n=252)$} \\
\hline Yes & $216(85.7)$ \\
\hline No & $36(14.3)$ \\
\hline \multicolumn{2}{|l|}{ Type of treatment given $(n=216)$} \\
\hline Hospital care & $71(32.9)$ \\
\hline Herbal medicine & $19(8.8)$ \\
\hline Sachet ORS & $66(30.6)$ \\
\hline Salt and sugar solution (at home) & $8(3.7)$ \\
\hline $\begin{array}{l}\text { Over the counter purchase of other drugs for } \\
\text { diarrhea treatment }\end{array}$ & $52(24.0)$ \\
\hline
\end{tabular}

ORT use compared to caregivers with at least primary education ( $\mathrm{OR}=0.620,95 \% \mathrm{Cl}=2.300-4.120)$. Similarly, caregivers who demonstrated poor knowledge had 0.640 times lesser ORT use for treating diarrhoea compared to caregivers with good knowledge $(\mathrm{OR}=0.640,95 \% \mathrm{Cl}=0.110-0.640)$.

\section{DISCUSSION}

Prevalence of diarrhoea was $61.5 \%$ in the study population. This results was higher than $10 \%$ reported as the national prevalence of diarrhoea among under-five Nigerian children in the 2013 NDHS report. ${ }^{[5]}$ The discrepancy could have been because the current study covered six months preceding the survey (which is one of the main rationale for this study), while the NDHS assessed diarrhoea occurrence within two weeks before the survey. Our results was also higher than the prevalence of diarrhoea reported in Jos, Plateau State, Nigeria. ${ }^{[18]}$ Again, this could have been because the current study was community-based, while the

Table 3. Awareness, knowledge, attitude and practice of participants on ORT

\section{n (\%)}

Ever heard about ORT $(n=410)$

Yes

$362(88.3)$

No

$48(11.7)$

Forms of ORT known ( $n=362)$

Sachet ORS

$282(78.0)$

Salt Sugar Solution

$62(17.1)$

Coconut water

Rice water

Garri water

$6(1.6)$

Knowledge on indications for ORT $(n=362)$

To stop diarrhea

$70(19.3)$

Prevent re-occurrence

Prevent bloody stool

$10(2.8)$

To replace lost nutrients

$88(24.3)$

Prevent weakness

$184(50.8)$

Overall knowledge score on ORT $(n=362)$

Good

Poor

Attitude towards ORT $(n=410)$

Positive

Negative

98 (23.9)

Used ORT for treating the last episode of

diarrhoea $(n=252)$

Yes

$145(57.5)$

No

107 (42.5)

ORS: Oral rehydration salt; ORT: Oral rehydration therapy. 


\begin{tabular}{|c|c|c|c|c|}
\hline & \multicolumn{2}{|c|}{ ORT Utilization } & \multirow[t]{2}{*}{$\mathbf{X}^{2}$} & \multirow[t]{2}{*}{$\mathbf{p}$} \\
\hline & $\begin{array}{c}\text { Yes } \\
\text { n (\%) }\end{array}$ & $\begin{array}{c}\text { No } \\
\text { n (\%) }\end{array}$ & & \\
\hline \multicolumn{5}{|l|}{ Age groups } \\
\hline$\leq 20$ years & $11(44.0)$ & $14(56.0)$ & 2.13 & 0.344 \\
\hline$>20$ years & $134(59.0)$ & $93(41.0)$ & & \\
\hline \multicolumn{5}{|l|}{ Gender } \\
\hline Male & $6(40.0)$ & $9(60.0)$ & 6.56 & 0.038 \\
\hline Female & $139(58.7)$ & $98(41.3)$ & & \\
\hline \multicolumn{5}{|l|}{ Religion } \\
\hline Christianity & $52(54.0)$ & $44(46.0)$ & 1.39 & 0.850 \\
\hline Islam & $93(59.6)$ & $63(40.4)$ & & \\
\hline \multicolumn{5}{|l|}{ Educational level } \\
\hline None & $20(48.0)$ & $22(52.0)$ & 13.10 & 0.041 \\
\hline At least primary & $125(60.0)$ & $85(40.0)$ & & \\
\hline \multicolumn{5}{|l|}{ Knows where to get } \\
\hline \multicolumn{5}{|l|}{ ORT easily } \\
\hline Yes & $137(60.1)$ & $91(39.9)$ & 11.60 & 0.003 \\
\hline No & $8(33.3)$ & $16(66.7)$ & & \\
\hline \multicolumn{5}{|l|}{ Knowledge on ORT } \\
\hline Good & $112(55.5)$ & $90(44.5)$ & 15.00 & 0.001 \\
\hline Poor & $33(66.0)$ & $17(34.0)$ & & \\
\hline \multicolumn{5}{|c|}{ Attitude towards ORT } \\
\hline Negative & $25(46.3)$ & $29(54.7)$ & 5.40 & 0.064 \\
\hline Positive & $120(61.0)$ & $78(59.0)$ & & \\
\hline
\end{tabular}

ORT: Oral rehydration therapy.

Chi-squared test.

Jos study was hospital-based. ${ }^{[18]}$ Thus, most cases would have resolved with appropriate home remedies without the need to visit hospital. ${ }^{[5]}$ Hence, diarrhoeal prevalence, as reported in the Jos hospital is more likely to be lower than the actual prevalence in the community. ${ }^{[18]}$ Meanwhile, the low socio-economic status of most of our participants and poor sanitary condition of the community could have accounted for the high diarrhoea burden in the study area. The current study revealed that only $10.7 \%$ of the participants attained tertiary education, $10.0 \%$ of them had no toilet facilities in their houses, $23.0 \%$ of them had pit latrine (which was unsanitary), while only $36.8 \%$ had access to borehole-water. These are strong enabling factors for the development of childhood diarrhoea disease in any community. Thus, the Nigerian government needs to prioritize rural communities in the provision of basic amenities.

Care was sought in healthcare facilities in only $32.9 \%$ of diarrhoea episodes in the current study location; $8.8 \%$ of diarrhoea cases were treated with herbal medicines. This is consistent with the 2013 Nigerian NDHS report, in which only $29 \%$ of diarrhoea cases were treated in the hospital. ${ }^{[5]}$ Treating diarrhoea with unprescribed drugs and ORS prepared with water of questionable quality portent a great danger to the health of children as this could worsen diarrhoea cases and increase the risk of dying from the disease. As stated by Toyobo, drinking-water supply is sub-optimal in our study population. ${ }^{[7]}$ The community also had poor environmental sanitation and housing standards. Thus, the risk of contamination of ORS prepared at most homes is extremely high, thereby worsening the health condition of a child presenting with diarrhoea. This calls for policies that will make appropriate water supply, sanitation, and hygiene facilities available in rural Nigeria. Also, there is a need to organize sensitization campaigns on diarrhoea disease and its management, particularly in the rural areas. Such campaigns should emphasise hospital management of diarrhoea episodes and how ORS can be hygienically prepared and administered at home before the child reaches the hospital.

Only $13.8 \%$ of all the participants who have heard of ORT had good knowledge about it but $76.1 \%$ of them had positive attitude to its use. Overall, ORS was utilized in treating only $57.5 \%$ of diarrhoea among under-five children in the study population. Our finding is in keeping with the result of a study conducted in Indian, in which $60 \%$ of mothers administered ORT to correct dehydration in children with diarrhoea disease. ${ }^{[19]}$ Moreover, Onwukwe et al. ${ }^{[20]}$ revealed that only $18.3 \%$ of caregivers of under-five children in South-Africa knew ORT could prevent dehydration in children having diarrhoea. It was observed that many children with diarrhoea episodes in the study setting still do not get treated with ORT despite its demonstrable ability to avert diarrhoea-related childhood mortalities. Hence, there is a need for policy formulation and/or review on diarrhoea treatment in rural Nigeria to fast-track the race towards reducing under-five mortality to as low as 25 per 1000 live births by the year 2030 in Nigeria. ${ }^{[2]]}$ Authors also call for qualitative research on the socio-cultural factors which may be militating against the use of ORT in treating diarrhoea disease in rural communities of Nigeria.

Female caregivers were more likely to have used ORT compared to men in the current study. This is not an unexpected finding because females tend to have more contacts with healthcare facilities than men in most Nigerian communities. Their contacts with health professionals, especially during antenatal periods and immunization sessions for their children, could have exposed them to adequate informa- 
Table 5. Predictors of ORT utilization in treating childhood diarrhoea

\begin{tabular}{|c|c|c|c|c|c|c|}
\hline & $\boldsymbol{\beta}$ & S.E. & Wald & $\mathbf{p}$ & AOR & $95 \% \mathrm{Cl}$ \\
\hline \multicolumn{7}{|l|}{ Age groups } \\
\hline$\leq 20$ years $^{(\mathrm{RC})}$ & \multirow[t]{2}{*}{0.947} & \multirow[t]{2}{*}{0.488} & \multirow[t]{2}{*}{3.774} & \multirow[t]{2}{*}{0.344} & \multirow[t]{2}{*}{0.551} & \multirow[t]{2}{*}{$0.321-1.893$} \\
\hline$>20$ years & & & & & & \\
\hline \multicolumn{7}{|l|}{ Gender } \\
\hline $\begin{array}{l}\text { Male }{ }^{(R C)} \\
\text { Female }\end{array}$ & -0.250 & 0.607 & 0.002 & 0.038 & 0.470 & $1.160-3.110$ \\
\hline \multicolumn{7}{|l|}{ Religion } \\
\hline $\begin{array}{l}\text { Christianity } \\
\text { Islam }\end{array}$ & 20.519 & 4.019 & 0.000 & 0.851 & 0.800 & $0.224-4.107$ \\
\hline \multicolumn{7}{|l|}{ Educational level } \\
\hline $\begin{array}{l}\text { None }^{(\mathrm{RC})} \\
\text { At least primary }\end{array}$ & -0.090 & 0.554 & 0.026 & 0.041 & 0.620 & $2.300-4.120$ \\
\hline \multicolumn{7}{|c|}{ Knows where to get ORT easily } \\
\hline $\begin{array}{l}\text { Yes } \\
\text { No }^{(\mathrm{RC})}\end{array}$ & 0.907 & 1.202 & 0.569 & 0.003 & 3.010 & $1.820-3.990$ \\
\hline \multicolumn{7}{|l|}{ Knowledge on ORT } \\
\hline $\begin{array}{l}\text { Good } \\
\text { Poor }^{(\mathrm{RC})}\end{array}$ & 0.007 & 0.352 & 0.000 & 0.001 & 0.640 & $0.110-0.640$ \\
\hline Attitude towards OI & & & & & & \\
\hline $\begin{array}{l}\text { Negative } \\
\text { Positive }\end{array}$ & 0.038 & 0.412 & 0.009 & 0.926 & 0.560 & $0.389-2.976$ \\
\hline Constant & -21.309 & 4.019 & 0.000 & 1.000 & 0.000 & \\
\hline
\end{tabular}

AOR: Adjusted odds ratio; Cl: Confidence interval; ORT: Oral rehydration therapy; RC: Reference category.

Binary logistic regression.

tion regarding the life-saving benefits of ORT in the management of diarrhoea cases culminating in actual practice. It is thus imperative to intensify efforts on providing more diarrhoea-treatment information to pregnant women during antenatal visits. Also, uneducated women were significantly less likely to have used ORT in the current study. This is consistent with a Cameroon study in which ORT utilization was significantly determined by parents' education. ${ }^{[22]}$ Educational attainment has been reported as a key determinant of positive health behaviour in most instances. ${ }^{[23]}$ Thus, the efforts of policy-makers and the governments at all levels must be geared towards raising awareness on the benefits of ORT use, particularly among the rural dwellers. Appropriate information on diarrhoeal causes, prevention and home remedies should be made available to caregivers, preferably in their local languages and facilitated with the use of appropriate channels of communication.

Participants who knew where to easily obtain sachet ORS constituted a significantly higher proportion of participants who used it in the current study. Hence, sachet ORS should be made more readily available at affordable prices and the use of herbal medication in treating diarrhoea in rural communities should further be discouraged due to their doubtful efficacies and many side effects. Caregivers who demonstrated good knowledge were significantly more likely to use ORT in the current study. This is consistent with the result of a study in Eastern Ethiopia in which knowledge was one of the main variables associated with ORT use. ${ }^{[24]} \mathrm{A}$ study in the Dominican Republic also supports this finding. ${ }^{[25]}$ Improving the socio-economic conditions of the rural dwellers will undoubtedly go a long way in preventing cases of diarrhoea disease among their children and in improving their health-seeking behaviour concerning childhood illnesses.

The limitation of this study was the presence of the memory factor. This study entailed remembrance of events that had happened over a six-month, recall bias is thus most likely, but that this study focused on the youngest children with diarrhoea episodes in the households visited could have minimised this bias. 


\section{CONCLUSION}

Our results underscore that diarrhoea is currently a menace in the study population. It is also glaring that ORT utilization in rehydrating children with diarrhoea episodes was sub-optimal in the community despite the life-saving potential of the therapy. Majority of caregivers did not also seek care in healthcare facilities. The existing diarrhoea control policies and programmes in Nigeria have to be harnessed and effective ones re-vitalized to attain the SDG regarding the well-being of the Nigerian children. Information from this study can thus be used in vital decision making by policymakers in the field of public health to develop a more cost-effective diarrhea control programme for the rural communities of Osun State.

\section{Disclosures}

Acknowledgement: Authors wish to acknowledge the paramount ruler of the Ejigbol and for giving us his permission and supports towards the success of this research in his domain. We also acknowledge the efforts of the medical students who assisted in data collection.

Peer-review: Externally peer-reviewed.

Conflict of Interest: Authors declared no conflict of interest in the conduct of this survey.

Ethics Committee Approval: Ethical approval to conduct this study was obtained from the Ethical Review Committee of Bowen University Teaching Hospital, Ogbomoso (Approval date: 20 Apr 2019, Approval number: NHREC/12/04/2012). This study only commenced when permission was granted by the king (Ogiyan of Ejigboland). Both verbal and written consents were obtained from each prospective participant before allowing them to participate. Participation was essentially voluntary, and confidentiality of the information supplied was also ensured by preventing the writing of names on the questionnaires. Data were also entered into the computer, which was only accessible to the researchers. Children with diarrhoea cases encountered during data collection were referred to the nearest health centre for appropriate care.

Authorship Contributions: Concept - A.I.; Design - Y.T.O.; Supervision - A.O.A.; Materials - O.K.I; Data collection \&/or processing - A.l.; Analysis and/or interpretation - A.l.; Literature search - A.l.; Writing - A.l.; Critical review - O.A.A.

\section{REFERENCES}

1. WHO. Diarrhoeal disease fact sheet, May 2017. Available at: http://www.who.int/mediacentre/factsheets/fs330/en/. Accessed Sep 30, 2019.

2. Kosek M, Bern C, Guerrant RL. The global burden of diarrhoeal disease, as estimated from studies published between 1992 and 2000. Bull World Health Organ 2003;81(3):197-204.

3. WHO. Water, sanitation and hygiene links to health. Available at: http://www.who.int/water_sanitation_health/publications/facts2004/en/. Accessed Oct 16, 2019.

4. UNICEF Data. Available at: https://data.unicef.org/topic/childhealth/diarrhoeal-disease/. Accessed Sep 30, 2019.

5. Nigeria Population Commission (NPC) Nigeria and ICF International, 2014. Nigeria Demographic and health survey 2013. Available at: https://dhsprogram.com/pubs/pdf/fr293/fr293. pdf. Accessed Jun, 2014.

6. WHO. Fact sheets. Children: improving survival and well-being. Available at: http://www.who.int/news-room/fact-sheets/ detail/children-reducing-mortality. Accessed Oct 16, 2019.

7. Toyobo AE. Evaluation of Borehole Water Supply Schemes in Ejigbo Local Government, Osun State, Nigeria. Journal of Resources Development and Management 2013;1:22-5.

8. UNICEF. Diarrhoea. Available at: https://www.unicef.org/ health/index_43834.html. Accessed Oct 16, 2019.

9. WHO/UNICEF. Joint statement: Clinical management of acute diarrhoea. Available at: https://www.unicef.org/publications/ files/ENAcute_Diarrhoea_reprint.pdf. Accessed Oct 16, 2019.

10. WHO. Bulletin of the World Health Organization. Declines in case management of diarrhoea among children less than five years old. Available at: http://www.who.int/bulletin/volumes/86/3/07-041384/en/. Accessed Oct 16, 2019.

11. UNICEF global databases 2017. Available at: https://data.unicef.org/topic/child-health/diarrhoeal-disease/. Accessed Oct 16, 2019.

12. Adimora GN, Ikefuna AN, Ilechukwu G. Home management of childhood diarrhoea: need to intensify campaign. Niger J Clin Pract 2011;14(2):237-41. [CrossRef]

13. Omole V, Wamyil-Mshelia T, Nmadu G, Usman N, Andeyantso E, Adiri F. Knowledge, attitude and practice of home management of diarrhoea among mothers of under-fives in Samaru, Kaduna State, Nigeria. Port Harcourt Med J 2019;13(1):19-25.

14. National Population Commission Nigeria, ICF. Nigeria Demographic and Health Survey 2018 Key Indicators Report. Available at: https://www.dhsprogram.com/pubs/pdf/FR359/ FR359.pdf. Accessed Oct 16, 2019.

15. Federal Republic of Nigeria. National Bureau of Statistics; Annual Abstract of Statistics. 2012. Available at: https://www. nigerianstat.gov.ng/pdfuploads/annual_abstract_2012.pdf. Accessed Oct 16, 2019.

16. Kish L. Survey sampling. New York: John Wiley \& sons, Inc; 1965.

17. Asakitikpi AE. Acute Diarrhoea: Mothers' Knowledge of ORT and Its Usage in Ibadan Metropolis, Nigeria. Ethno Med 2010;4(2):125-30. [CrossRef]

18. Yigwan CS, Okolo SN. Prevalence of diarrhoea disease and risk factors in Jos University Teaching Hospital, Nigeria. Annals of African Medicine 2012;11(4):217-21. [CrossRef] 
19. Datta V, John R, Singh VP, Chaturvedi P. Maternal knowledge, attitude and practice towards diarrhoea and Oral rehydration therapy in rural Maharashtra. Indian Journal of Paediatrics 2001;68(11):1035-7. [CrossRef]

20. United Nations. Sustainable Development Goals Report SDG Indicators. Available at: https://unstats.un.org/sdgs/report/2019/. Accessed Jan 27, 2020.

21. Onwukwe S, van Deventer C, Omole O. Evaluation of the use of oral rehydration therapy in the management of diarrhoea among children under 5: Knowledge attitudes and practices of mothers/caregivers. South African Family Practice 2016;58(2):42-7. [CrossRef]

22. Essomba NE, Kedy Koum DC, Adiogo D, Ngwe MI, Coppieters Y. Use of oral rehydration therapy in the treatment of child- hood diarrhoea in Douala, Cameroon. Malawi Medical Journal 2015;27(2):60-4. [CrossRef]

23. Ihaji E, Gerald EU, Ogwuche CHE. Educational Levels, sex and church affiliation on health seeking behaviour among parishioners in Makurdi metropolis of Benue State. Journal of Educational Policy and Entrepreneurial Research 2014;1(2):311-6.

24. Bezatu M, Yemane B, Alemayehu W. Predictors of oral rehydration therapy use among under-five children with diarrhoea in Eastern Ethiopia: a community-based case control study. BMC Public Health 2012;12:1029. [CrossRef]

25. McLennan JD. Home management of childhood diarrhoea in a poor peri-urban community in Dominican Republic. Journal of Health, Population and Nutrition 2002;20(3):245-54. 